\title{
COVID Vaccination in Cancer Patients: What Vaccination Priority Strategies Should There Be?
}

\author{
Nicola Silvestris ${ }^{1,2 *}$, Oronzo Brunetti ${ }^{1}$, Renato Bernardini ${ }^{3 \dagger}$ and Saverio Cinieri ${ }^{4 \dagger}$ \\ ${ }^{1}$ Medical Oncology Department, IRCCS IstitutoTumori "Giovanni Paolo II", Bari, Italy, ${ }^{2}$ Department of Biomedical Sciences and \\ Human Oncology, University of Bari "Aldo Moro", Bari, Italy, ${ }^{3}$ Section on Pharmacology, Department of Biomedical and \\ Biotechnological Sciences, University of Catania School of Medicine, Catania, Italy, ${ }^{4}$ Medical Oncology \& Breast Unit, Antonio \\ Perrino Hospital, Brindisi, Italy
}

Keywords: COVID-19, SARS-CoV-2, vaccine, cancer patients, chemotherapy

\section{INTRODUCTION}

OPEN ACCESS

Edited by:

Dana Kristjansson,

Norwegian Institute of Public Health

(NIPH), Norway

Reviewed by:

Marianna De Camargo Cancela, National Cancer Institute (INCA), Brazil

Daniele Santini,

Campus Bio-Medico University, Italy

${ }^{*}$ Correspondence: Nicola Silvestris n.silvestris@oncologico.bari.it

${ }^{\dagger}$ These authors share senior authorship

Specialty section: This article was submitted to Cancer Epidemiology and Prevention, a section of the journal

Frontiers in Oncology

Received: 14 December 2020 Accepted: 13 January 2021 Published: 04 February 2021

Citation:

Silvestris N, Brunetti O, Bernardini R and Cinieri S (2021) COVID

Vaccination in Cancer Patients: What Vaccination Priority Strategies Should There Be? Front. Oncol. 11:641388. doi: 10.3389/fonc.2021.641388
At the height of the second wave of the COVID-19 pandemic, two fat lipid nanoparticle-vehicled RNA vaccines for SARS-COV-2 completed phase 3 trials with excellent results in terms of safety and efficacy $(1,2)$. In particular, the Pfizer vaccine trial considered 43,584 enrolled individuals with 170 COVID-19 positive subjects (162 and 8 in placebo and vaccine groups, respectively) (1). Similarly, the Moderna vaccine trial reported 90 and 5 infections (out of 30,000 volunteers enrolled) in placebo and vaccine groups, respectively. Both vaccines achieved 95\% efficacy (2). Fever, fatigue, and headache were the most common side effects with higher incidence for Moderna vs the Pfizer vaccine $(1,2)$.

\section{BACKGROUND AND RATIONALE}

Considering the urgent need to define priorities in selecting the subgroups of the population requiring such a vaccination, national vaccination plans have been elaborated. In particular, the Italian national strategic plan lists the following priority categories: i) doctors and health professionals; ii) residents and staff of residential care centers for the elderly; iii) elderly population (at first those aged over 80 years, and then between 60 and 79 years); and iv) population with at least one chronic comorbidity (3). According to these indications, it is estimated that 27 million Italian people (20 million belonging to the first three categories and 7 million with chronic diseases) will require early vaccination (3). Considering that two doses are scheduled for each patient, it will be necessary, in the beginning, to define who should be vaccinated among individuals with chronic diseases. Oncologic patients represent one of the most fragile categories (4). In this line, a retrospective study conducted at the Memorial Sloan Kettering Cancer Center showed that hematologic malignancies are associated with increased COVID-19 severity (HR 1.90; 95\% CI: 1.30-2.80), and lung cancer patients experienced a higher rate of serious COVID19 symptoms (HR 2.0; 95\% CI: 1.20 - 3.30) (5). The rate of adverse events was lower in a timematched population of patients with cancer without COVID-19.

According to AIRTUM data, about $6 \%$ of the Italian population is affected by a neoplastic disease, corresponding to over 3.5 million people (6). Keeping these data in mind, the key question is: what vaccination priority strategies in cancer patients should there be? 


\section{DISCUSSION}

It is well known that cancer patients do not represent a homogeneous population according to the four categories under which cancer treatments fall proposed by Schrag et al. (curative potential, moderate clinical importance, marginal impact on quality or quantity of life, and survivorship and surveillance) (7). According to these categories and the available therapeutic strategies, we believe that the following subsets of cancer patients should be vaccinated first:

i. subjects undergoing radical surgery who are candidates for adjuvant systemic treatments starting within 1-2 months after surgery aimed to improve both relapse-free survival and overall survival (8); in these cases, the first dose of the vaccine should be administered within 7-10 days from surgery and the second after another 3 weeks, taking into account the timing of the adjuvant treatments. A similar approach is considered in the management of cancer patients who underwent splenectomy requiring pneumococcal and meningococcal vaccinations before the beginning of systemic therapies (9);

ii. patients with advanced disease (especially lung cancer patients) whose tumor burden and biological assessment allows for a one-month postponement of the beginning of systemic treatments.

\section{REFERENCES}

1. Polack FP, Thomas SJ, Kitchin N, Absalon J, Gurtman A, Lockhart S, et al. C4591001 Clinical Trial Group. Safety and Efficacy of the BNT162b2 mRNA Covid19 Vaccine. N Engl J Med (2020) 383(27):2603-15. doi: 10.1056/NEJMoa2034577

2. Moderna. Moderna's COVID-19 Vaccine Candidate Meets its Primary Efficacy Endpoint in the First Interim Analysis of the Phase 3 COVE Study (2020). Available at: https://investors.modernatx.com/news-releases/news-releasedetails/modernas-covid-19-vaccine-candidate-meets-its-primary-efficacy (Accessed December 12, 2020).

3. Italian Minister of Health. Vaccinazione anti-SARS-CoV-2/COVID-19 PIANO STRATEGICO. Available at: http://www.salute.gov.it/imgs/C_17_notizie_ 5202_1_file.pdf (Accessed December 12, 2020).

4. Brunetti O, Derakhshani A, Baradaran B, Galvano A, Russo A, Silvestris N. COVID-19 Infection in Cancer Patients: How Can Oncologists Deal With These Patients? Front Oncol (2020) 10:734. doi: 10.3389/fonc.2020.00734

5. Jee J, Foote MB, Lumish M, Stonestrom AJ, Wills B, Narendra V, et al. Chemotherapy and COVID-19 Outcomes in Patients With Cancer. J Clin Oncol (2020) 38:3538-46. doi: 10.1200/JCO.20.01307

6. AIRTUM. I NUMERI DEL CANCRO IN ITALIA (2020). Available at: https:// www.registri-tumori.it/cms/sites/default/files/pubblicazioni/new_NDC2020operatori-web.pdf (Accessed December 12, 2020).
Recently, ESMO published 10 statements to address these issues and concerns (9). However, several questions still remain open for the other subset of cancer patients: which criteria could be applied for advanced patients during systemic treatments, including chemotherapy, targeted therapies, and immunotherapy? What could the management be for patients under hormonal therapies? Are cancer patients previously infected by SARS-CoV2 candidates to receive the vaccine? What kind of interactions could occur between antiviral vaccines and both antineoplastic therapies and the associated ancillary drugs including steroids? How long should immunity be expected to last in these patients?

Today, national health institutions and the scientific community are urged to answer these questions. To fulfill this commitment, in the absence of published data, large-scale collaborative post-trial, and registry monitoring studies are required.

\section{AUTHOR CONTRIBUTIONS}

Conception or design of the work: NS. Literature research: OB. Drafting and writing the article: $\mathrm{OB}$, NS. Critical revision of the article: RB, SC. All authors contributed to the article and approved the submitted version.

7. Schrag D, Hershman DL, Basch E. Oncology practice during the COVID-19 pandemic. JAMA (2020) 323:2005-6. doi: 10.1001/jama.2020.6236

8. Biagi JJ, Raphael MJ, Mackillop WJ, Kong W, King WD, Booth CM. Association between time to initiation of adjuvant chemotherapy and survival in colorectal cancer: a systematic review and meta-analysis. JAMA (2011) 305:2335-42. doi: 10.1001/jama.2011.749

9. Di Sabatino A, Lenti MV, Tinozzi FP, Lanave M, Aquino I, Klersy C, et al. Vaccination coverage and mortality after splenectomy: results from an Italian single-centre study. Intern Emerg Med (2017) 12:1139-47. doi: 10.1007/s11739017-1730-9

Conflict of Interest: The authors declare that the research was conducted in the absence of any commercial or financial relationships that could be construed as a potential conflict of interest.

Copyright (c) 2021 Silvestris, Brunetti, Bernardini and Cinieri. This is an open-access article distributed under the terms of the Creative Commons Attribution License (CC BY). The use, distribution or reproduction in other forums is permitted, provided the original author(s) and the copyright owner(s) are credited and that the original publication in this journal is cited, in accordance with accepted academic practice. No use, distribution or reproduction is permitted which does not comply with these terms. 